\title{
Optical features of flax fibers coming from the Turin Shroud
}

\author{
Giulio Fanti ${ }^{\mathrm{a}}$ \\ Department of Industrial Engineering, University of Padova, Padova, Italy
}

\begin{abstract}
This paper presents a study of flax fibers coming from the TS (Turin Shroud) and evidences their peculiar features if compared with recent ones. A further comparison between image-fibers and non-image-fibers shows both structural and chemical differences especially in correspondence of the external layer about $200 \mathrm{~nm}$ thick.

The PLM (Polarized Light Microscopy) is used to evidence the various features of the TS fibers, and these features are then explained also at the light of the ancient procedure used to produce fibers from flax plants.

Optical microscope and SEM (Scanning Electron Microscope) are used to better show the various fiber's features evidencing the presence of impurities and defects.

Finally an opto-chemical analysis is performed showing results of TS fibers relative to CIELAB values, FT-IR ATR and Raman tests also trying to interpret, from a chemical point of view, some peaks present in the spectra.
\end{abstract}

\section{Introduction}

The Turin Shroud (TS) is a $4.4 \mathrm{~m}$ long and $1.1 \mathrm{~m}$ wide linen sheet that enveloped the corpse of a scourged, thorn-crowned, and crucified man stabbed in the side by a sharp object compatible with a lance $[1,2]$. Many other marks are visible like those caused by blood, fire, water, and folding that partially obscure the double, front and back, body image.

Many believe the TS is the burial cloth in which Jesus Christ was enveloped and placed in a Palestine tomb about 2000 years ago, but some still declare that it is a fake, therefore it the most important but also most controversial Relic of Christianity.

After the photographs made by Pia in 1898 when the body image resulted as a photographic negative [3], the TS image gained a lot of scientific interest. This year marked the beginning of the scientific era for the Relic that produced hundreds of discoveries and publications [1, 4].

In 1931, G. Enrie [5] photographed the TS at high resolution using orthochromatic plates; the luminance levels revealed a 3D image of a human body when interpreted as mapping cloth to body distance [6].

The most wide and detailed scientific analysis of the TS was performed in 1978 by the STURP (Shroud of TUrin Research Project) [1, 4] that founded the modern approach to the Relic. These studies, afterwards endorsed by newer analyses, confirmed that there are no scientific explanations for the body image formation.

\footnotetext{
a e-mail: giulio.fanti@unipd.it
}

This is an Open Access article distributed under the terms of the Creative Commons Attribution License 4.0, which permits unrestricted use, distribution, and reproduction in any medium, provided the original work is properly cited. 
The TS body image is extremely superficial; in some areas of the frontal image, such as those of the face and perhaps the hands, it appears superficial on both sides [7]. This important finding has recently been questioned [8] but it has been confirmed again [9] showing some inconsistencies of the arose doubts. Many other particular features impossible to reproduce all together are reported in the literature [10]. A detailed description of "superficiality" is reported in [11, 12].

This paper presents the particular features of TS fibers from an optical point of view, also discussing in the details their optical patterns that result from a cross-polarized analysis. It was just this technique that allowed the author to select TS fibers from others in the vacuumed dusts during 1978 test campaign $[13,14]$ and to perform alternative dating of the Relic showing that it was made in the First Century A.D. $[15,16]$.

\section{Polarized Light Microscopy}

Us Polarized Light Microscopy (PLM) [17] is an important mean to characterize the TS fibers and it is necessary to shortly introduce it before to discuss the features of TS fibers.

The human eye-brain system has no sensitivity to both the vibration directions and phase of light, but polarized light can be used to detect a color effect of the sample related to the phase.

The PLM includes a technique of illumination of the sample using cross-polarized light. The petrographic microscope is an instrument that allows to study a birefringent sample, using PLM and in particular to look at it using cross-polarization.

Directly transmitted light, polarized by a first filter, reaches the sample under analysis and then passes through a second polarizer, named analyzer, generally orientated at $90^{\circ}$ to the illumination, but that can be rotated of $360^{\circ}$ to enhance some details of the sample.

In the $90^{\circ}$ configuration, the polarizer and the analyzer are said to be crossed, with no light passing through the system and a dark view-field results in the eyepieces; only the light passing through the birefringent sample is therefore visible.

As the linen fibers are birefringent, the polarized light interacts strongly with the fiber and so a particular shape can be photographed showing many details that are not detectable in simple visible light.

The PLM provides information on absorption color and optical path boundaries between samples of differing refractive indexes, in a manner similar to bright-field illumination. Furthermore, the optical properties relative to anisotropy reveal information concerning the structure and composition of materials that are useful for identification and diagnostic purposes.

When a polarized light passes through a birefringent sample as a flax fiber, the phase difference between the fast and slow directions varies with its thickness and light wavelength. The optical path difference, also named retardation $r$ is defined as:

$$
r=t \Delta n
$$

where $\mathrm{t}$ is the thickness of the sample and $\Delta \mathrm{n}$ the difference between the two refractive indexes of the birefringent material, that in the case of flax fibers is 0.07 [17].

If the light is monochromatic of wavelength $\lambda$, this optical path difference produces a phase difference $\phi$ between the light passing in the two vibration directions of the linen sample:

$$
\phi=2 \pi r / \lambda=2 \pi t \Delta n / \lambda .
$$

If $r=\lambda / 2$, then $\phi=\pi$ all the light passes through the analyzer. If instead $r=\lambda$, then $\phi=2 \pi$ a black background area results. If a polychromatic light passes through a birefringent sample only one specific wavelength will meet the condition $r=\lambda / 2$.

Using the Michel-Levy interference color chart [17], it is possible to graphically relate sample thickness, retardation (optical path difference) and birefringence (numerical difference between 


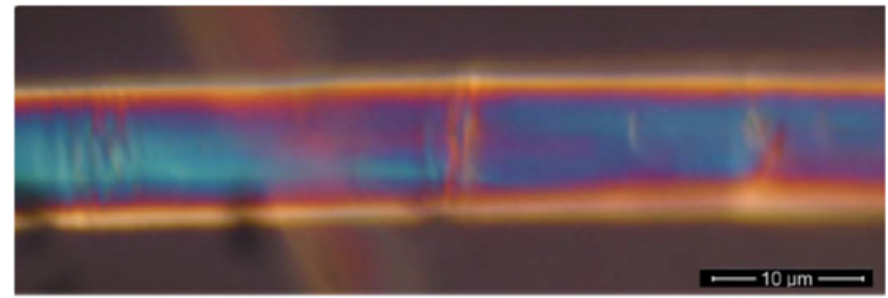

Figure 1. Modern flax fiber seen in incident cross-polarized light.

the refractive indices) each other for particular views of birefringent substances. Therefore if the birefringence of the sample is known, with this chart the sample thickness can be determined from the resulting color and vice-versa.

In the case of a modern flax fiber, see Fig. 1, that has a reduced number of defects, it is relatively easy to detect its diameter using the above mentioned Michel-Levy Chart: in reference to a 0.07 birefringent index, and to the Sky-blue color $(r=664 \mathrm{~nm})$ of the fiber center, it corresponds a fiber thickness of $11 \mu \mathrm{m}$.

Going from the center to the edges, the fiber's color becomes redder up to reach the yellow color $(\mathrm{r}=320 \mathrm{~nm})$; for example, in correspondence of this yellow color can be found a thickness of about $5 \mu \mathrm{m}$. The blue color becomes redder $(\mathrm{r}=536 \mathrm{~nm})$ in the center of the same flax fiber, thus indicating the presence of a fiber flattening from $11 \mu \mathrm{m}$ to about $9 \mu \mathrm{m}$.

The PLM can be a very simple tool to identify the fibers' shape but there are some additional facts that make this analysis less easy. They are the following:

-a. The flax fiber is not only composed of cellulose but it is made of other materials (polysaccharides prevalently different from cellulose) that have different behavior and that therefore can alter the resulting colors seen in cross-polarized light.

-b. The refractive indexes of the birefringent material are not always constant because they also depend on the mechanical stress applied to the fiber. Moreover, according to the II law of photoelasticity, the difference between the refractive indexes $\Delta \mathrm{n}$ is proportional to the difference between the principal stresses.

-c. Some defects and discontinuities, like the presence of the dislocations (or kink bands) [18] in the flax fiber, that comprehend growth nodes and other defects, alter the PLM response thus complicating the interpretation of the resulting image.

\section{TS flax fibers morphology using optical, petrographic and scanning electron microscopes}

Ancient fibers in general, and therefore also those coming from the TS, show a morphology more complicated than that of modern fibers, see Fig. 1. This section discusses the structure of some TS fibers seen using optical or petrographic microscopes and SEM.

Figure 2 compares an image-fiber with a non-image one coming from STURP-1EB Mylar tape sampled by R. Rogers in 1978; this image has been acquired using an optical microscope in transmitted light. Like the flax fibers in general, the non colored ones are less visible in simple transmitted light because the refraction index of flax is similar to that of the surrounding air or glue. The edges of them are in fact more or less easy to see depending on the refraction index of the substance in which they are immersed. The color of the image-fiber, that is caused by an oxidation, dehydration and conjugation of 


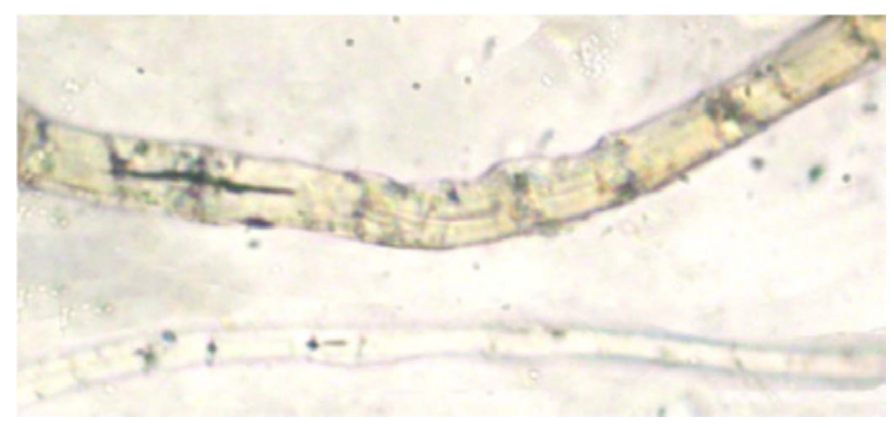

Figure 2. Image-fiber (above) and non-image fiber (below) coming from STURP-1EB tape taken from the right ankle of the dorsal TS body image, seen through an optical microscope in transmitted light.

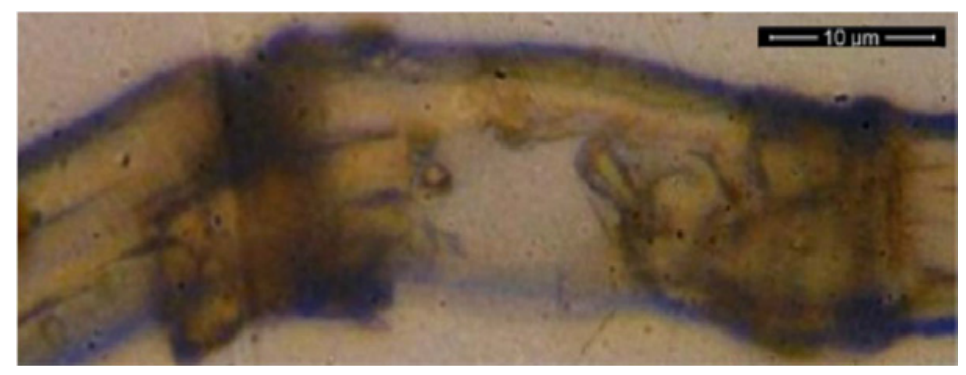

Figure 3. Image-fiber [9] coming from STURP-1EB tape (taken from the right ankle of the TS Man) seen in transmitted light. The colored layer about $200 \mathrm{~nm}$ thick of polysaccharides, named PCW of the flax fiber, is evident if compared with the uncolored cellulosic SCW.

the external polysaccharides or polyphenols layer [10], makes instead the fiber more simple to detect in transmitted light.

The colored fiber of Fig. 2 shows a variable color intensity that increases going from the left to the right and some defects are evident. Some of them appear on the non colored fiber of Fig. 2 too.

For example a longitudinal cut of the upper fiber (black line) is well evident and other pseudocircular defects (dark points) are almost uniformly distributed along the length of the two fibers. Some of them can be related to growth nodes while other dark spots can be related to lignin concentrations.

Figure 3 shows a peculiar feature of the TS image fibers: the color only resides on the external layer, about $200 \mathrm{~nm}$ thick of polysaccharides named Primary Cell Wall (PCW) [11]. The PCW, about $200 \mathrm{~nm}$ thick, is mainly constituted by hemicelluloses, that is composed of shorter chains of the same glucose "brick" units that constitute the cellulose in the Secondary Cell Wall (SCW). This last is thicker and prevalently composed of cellulose.

We can therefore deduce that the color of the TS image is extremely superficial also at microscopic level because it resides on the external layer of flax fibers. This PCW has been isolated after sampling with Mylar sticky tapes in 1978; Fig. 4 shows an example.

A SEM photo of a TS fiber, see Fig. 5 evidences a dislocation (growth node) that consist in a thickening of the diameter. The not smooth surface of the fiber is typical of an ancient flax and it can be related to some incrustation that an Energy-dispersive X-ray spectroscopy has shown to be also of calcareous type. Instead Fig. 6 shows a TS fiber prevalently encrusted of mildew. 


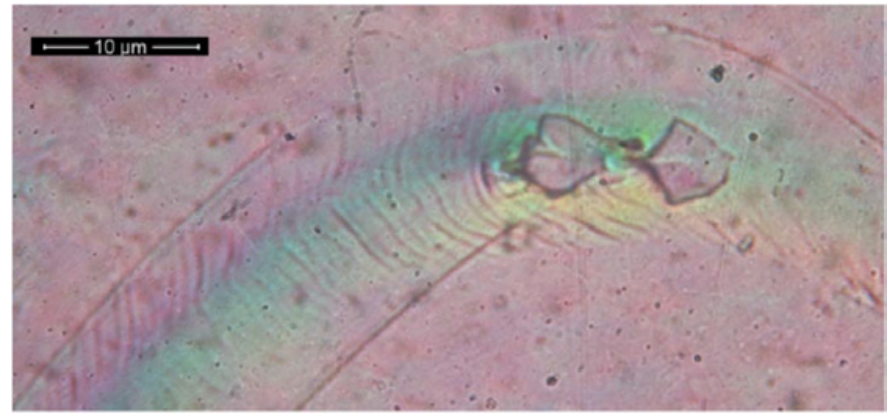

Figure 4. A so-called "Ghost" by R. Rogers who sampled this STURP-1EB tape (taken from the right ankle of the TS Man). The photomicrograph has been taken in transmitted light using a petrographic microscope. This is probably a PCW that was pulled off the corresponding flax fiber during sampling and was trapped in the glue of the tape.

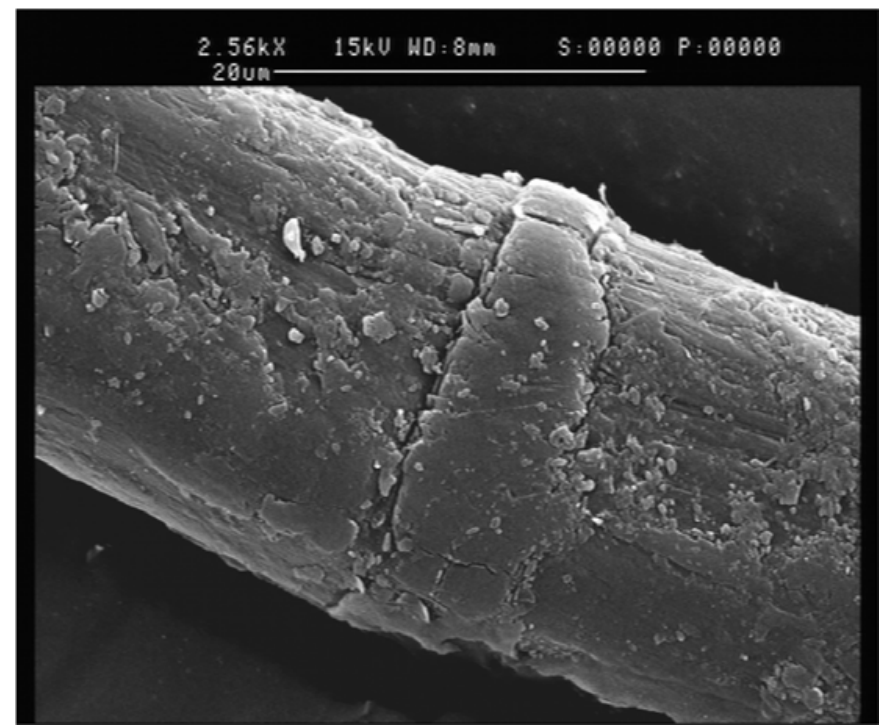

Figure 5. SEM photograph of a flax fiber coming from the TS showing external incrustation and a dislocation that can be due to a growth node.

\section{Morphology of TS flax fibers using PLM}

PLM is a useful technique to evidence the particular features of flax fibers; for example Fig. 7 shows the details of a broken TS fiber (coming from STURP-1EB) in correspondence to a dislocation (or kink band), similar to that shown in Fig. 5.

From the use of the Michel-Levy Chart, it results that the left part of this fractured fiber has a maximum diameter of about $12 \mu \mathrm{m}$ (to be compared with Fig. 1). The sub-micrometer fibrils that compose the flax fibers, are visible in the break, as a badly resolved bundle (due to the resolution limits of an optical microscope). The part of the fiber on the right, of similar color, and therefore of similar diameter of the left side, appears more defective showing many longitudinal breaks on its surface.

Some of the TS fibers analyzed show an encrusted surface as that shown in Fig. 8: in fact the boundaries are not well defined due to the presence of additional material consisting in calcareous particles and dirty. 


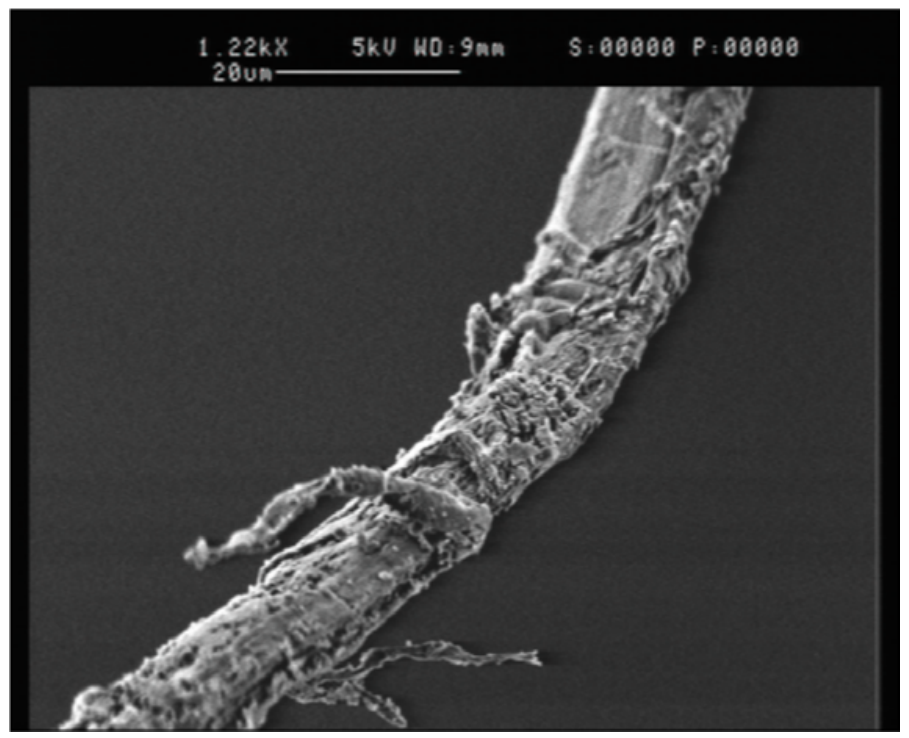

Figure 6. SEM photograph of a flax fiber coming from the TS showing a surface encrusted of mildew.

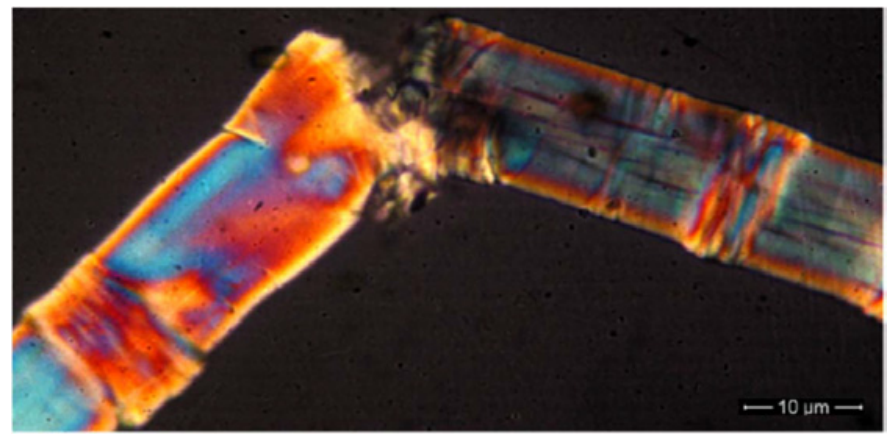

Figure 7. PLM photograph of a broken flax fiber coming STURP-1EB tape.

PLM analysis of TS fibers coming from the back TS image, in correspondence of the gluteal area, evidences a new feature that can be interesting also for the explanation of how the body image formed. Figure 9 shows one of the various TS fibers coming from this area presenting a peculiar periodical defect; it consists in the absence of color in PLM and then the supposed absence of SCW in correspondence of pieces of fibers having a length of 50-150 $\mu \mathrm{m}$ [In fact, having a negligible retardation (Eq. (1)) due to its very small thickness, the PCW shows no color, while the whole fiber (PCW+SCW) shows colors depending on its thickness in PLM]. Knowing that:

- a TS thread has a diameter of 100-350 $\mu \mathrm{m}$, comparable with the length of the periodical effect;

- an absence of color leads to think to a piece of "burnt" and/or "dried" fiber in which only the external wall (PCW) seems to remain, appearing as if it was in some way emptied of the internal cellulosic layer, it can be hypothesized that the imaging formation process, perhaps also related to a Corona Discharge [19], has acted in the following way.

Only the topmost fibers of a TS weaved thread have been exposed to the radiation and the result of this exposition is almost periodical along the thread of the fabric because a part of these fibers was exposed, 


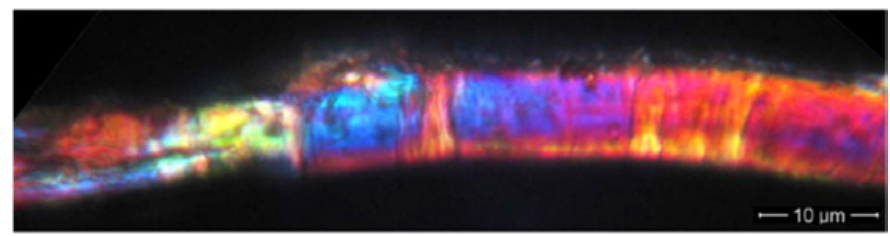

Figure 8. PLM photograph of a TS flax fiber showing an encrusted surface and many dislocations (or kink bands).
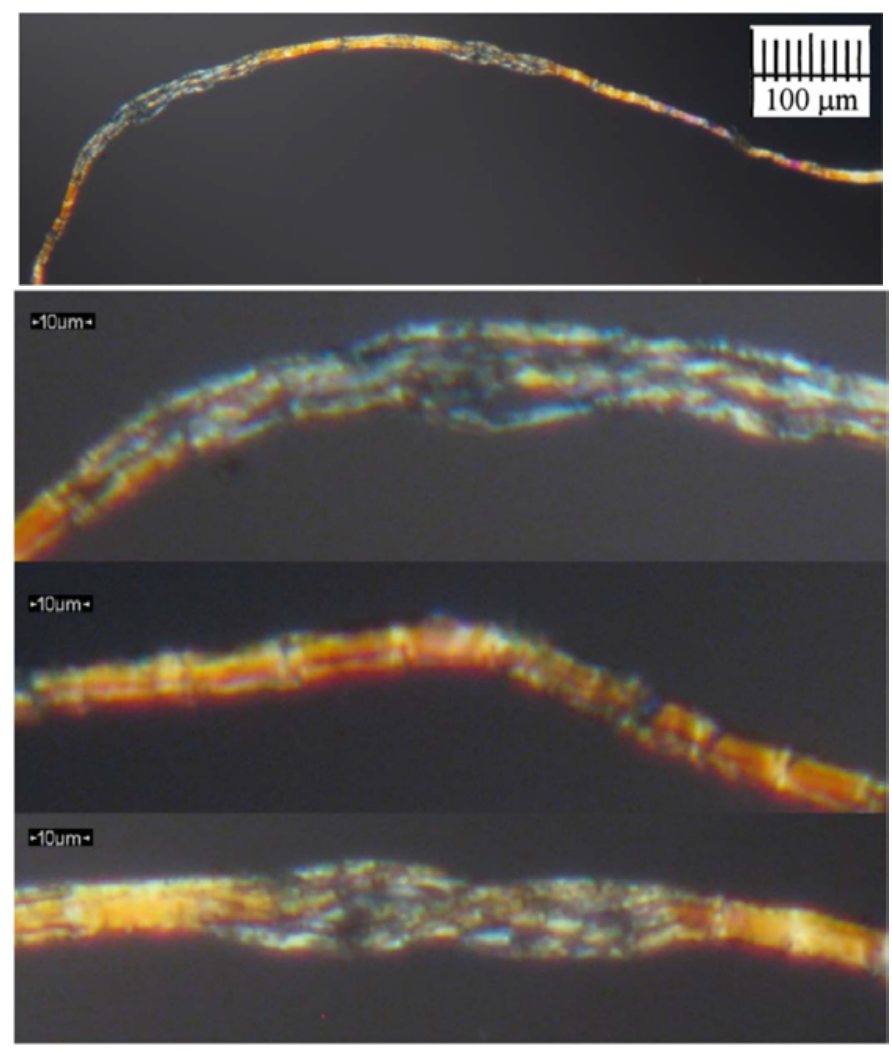

Figure 9. PLM photograph of a TS flax fiber coming from gluteal area, with three details. An almost periodical defect, having a length of $50-150 \mu \mathrm{m}$, is probably related with the weaving crossing threads.

but the other part was protected by other threads of the weaving. In fact crossing threads could have produced a periodical masking effect along the exposed threads. Alternative to this interpretation there are under examination other effects like mechanical ones.

While recent flax fibers seen in PLM show a simpler configuration like that reported in Fig. 1, ancient flax fibers show a more complex structure. In particular a greater number of defects like dislocations (or kink bands) seems to be detectable in them. A recent work [20] does not reach this conclusion stating that "the dislocations in Turin Shroud flax fibres appear to be similar in amount, sizes and distances to dislocations in modern hemp fibres.", but looking at the Table 1 of the same paper, it results that the mean "longitudinal distance between dislocations" is $7.2 \mu \mathrm{m}$ in the case of the TS fibers while it ranges from $8.0 \mu \mathrm{m}$ to $15.1 \mu \mathrm{m}$ in the four cases considered for hemp, the higher value just corresponding to 


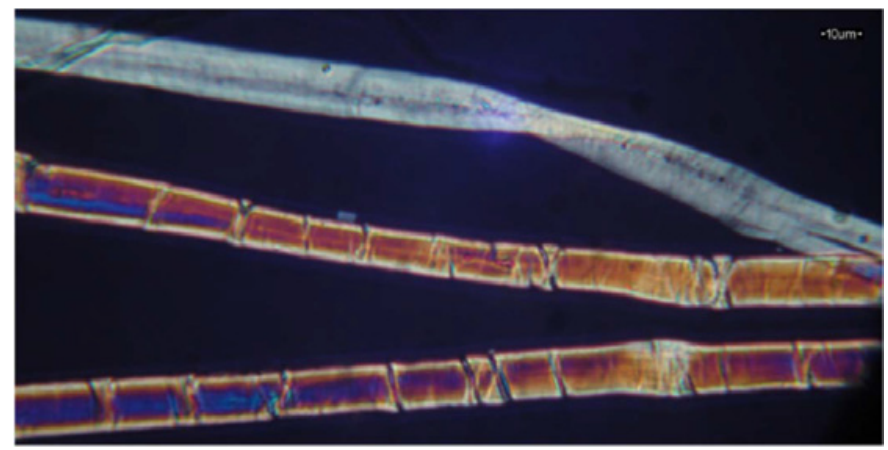

Figure 10. PLM photograph of two TS flax fibers and a cotton fiber (on the top) coming from a corner of the TS; many dislocations are evident.

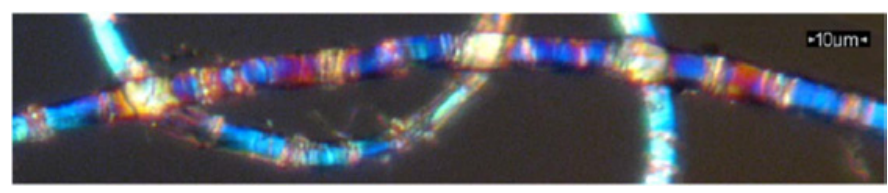

Figure 11. PLM photograph of a TS flax fiber coming from the gluteal area; many dislocations are evident.

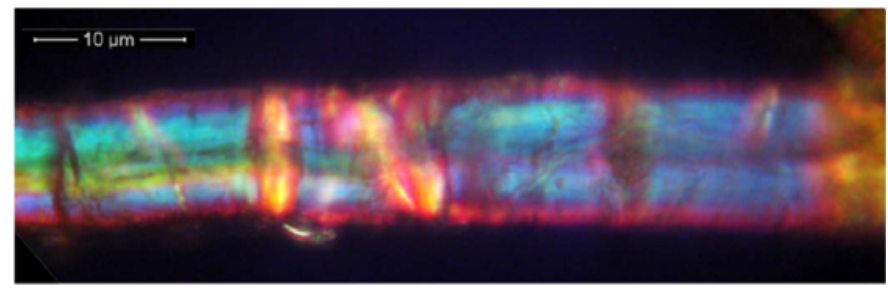

Figure 12. PLM photograph of a flax fiber coming from an Egyptian fabric (Turin Museum, Cat. 731) dated 2400 BC showing many defects.

yarn hemp. This result seems to contradict the previous sentence and to be in agreement with the results here discussed.

Figure 10 shows two flax fibers coming from a corner of the TS with a cotton fiber found in the same thread as contaminant (incidentally about one cotton fiber has been found over 100 flax fibers). Figure 11 shows another flax fiber coming from the TS (gluteal area) in which a great number of defects is evident. If compared with the flax fiber of Fig. 1, it results that the number of dislocations increases a lot in the case of TS fibers. A PLM photograph of a flax fiber coming from an Egyptian fabric (Turin Museum, Cat. 731) dated 2400 BC, see Fig. 12 confirms the increasing number of defects present in ancient flax fibers.

The presence of a greater number of dislocations (and of other defects) in ancient fibers than in modern ones is very frequent and it is certainly due to the fact that defects increase with time for many reasons, but it can also be related to the manual preparation procedure of the flax.

In the ancient times, according with Pliny the Elder [21] "the stems [...] are dried in the sun, then, once dried, are crushed on a stone with a tow-hammer." The stalks were beaten and crushed on a stone using specific tools. This procedure justifies the particular feature of ancient flax fibers that are well 


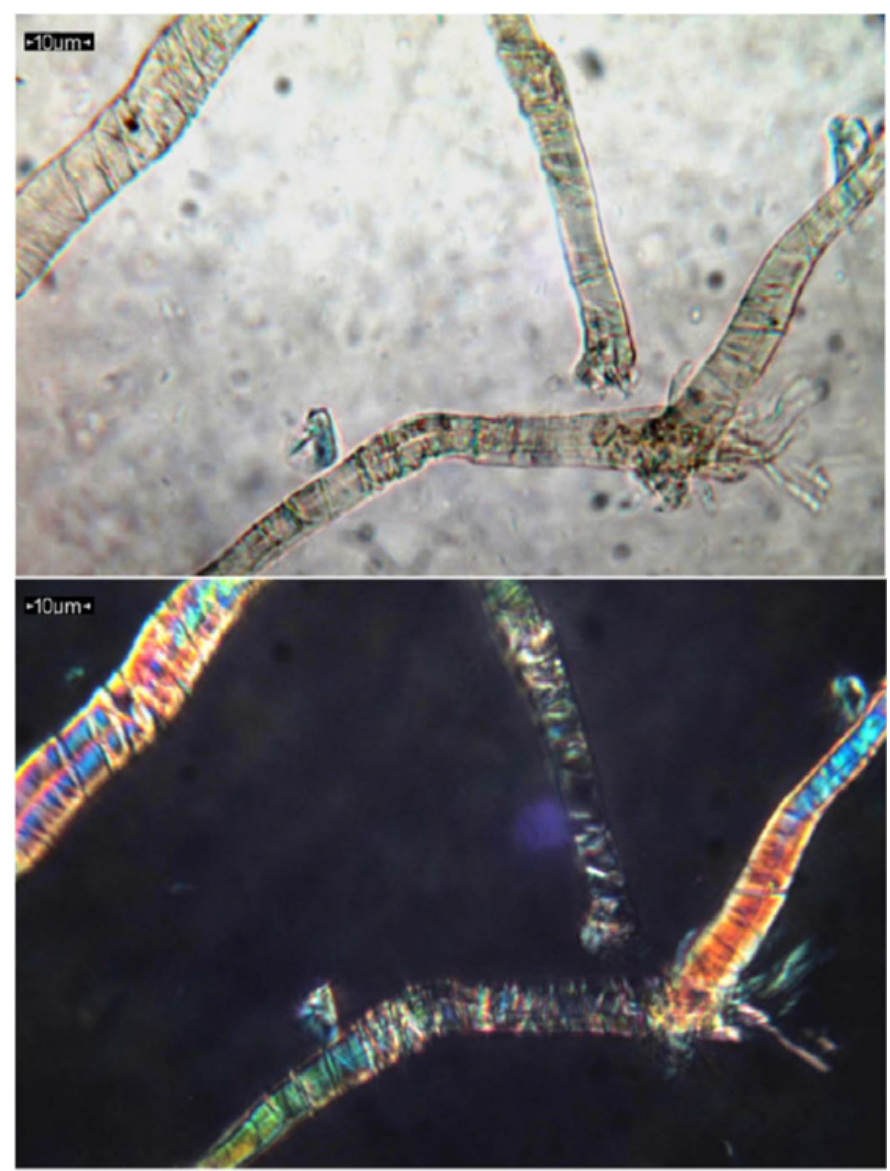

Figure 13. Image-fibers seen in transmitted visible light (above) and in cross-polarized light (below) coming from STURP-1EB tape taken from the right ankle of the dorsal body image: the corrugation of PCW is evident.

distinguishable in PLM from the modern ones because filled of dislocations. Modern flax fibers in fact are not subjected to this beating procedure that surely increases the number of defects.

\section{A PLM feature of TS colored fibers}

The external structure of TS image-fibers is peculiar and worth of a detailed discussion. Image-fibers, see Figs. 13, 14 and 15 (taken from STURP-1EB tape coming from the right ankle of the dorsal body image), have a corrugated surface that is not typical of TS non-image flax fibers, but that is typical of flax fibers exposed to intense sources of radiation. In fact experimentally colored fibers of flax exposed to Corona Discharge [19], see Fig. 16 and to Excimer Lasers [22], see Fig. 17, show a similar feature.

The PCW corrugation can be explained as the result of a SCW shrinking caused by a chemical modification that could be related to dehydration, oxidation and/or conjugation produced by intense radiations. This process of SCW shrinking can also be increased by aging and this hypothesis can also help to explain the increasing of the number of dislocations per unit length with age of the flax fibers.

The corrugated surface detected in the PCW, supposed to be due to the SCW shrinking, can be reproduced with the following experiment that considers an enlarged model of a flax fiber. Take a rubber-band, like that shown in Fig. 18, and cover it with a sticky tape that is stiffer than the rubber. 


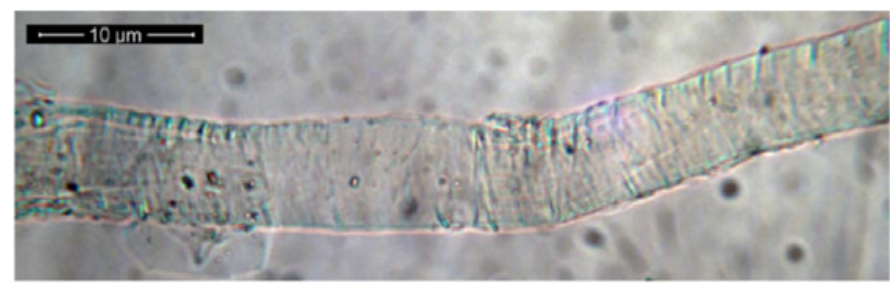

Figure 14. Image-fiber seen in transmitted visible light coming from STURP-1EB tape taken from the right ankle of the dorsal body image: also without the use of PLM, the corrugation of PCW is distinguishable.



Figure 15. Image-fiber seen in cross-polarized light coming from STURP-1EB tape taken from the right ankle of the dorsal body image: the corrugation of PCW is well evident.

The rubber-band represents the cellulosic SCW while the sticky tape represents the polysaccharides PCW of the fiber.

-1. If the flax fiber (rubber-band) is not loaded or deformed, the PCW (sticky tape) shows almost no dislocations as we see in modern fibers (Fig. 18, upper image, left side).

-2. If the flax fiber (rubber band) is deformed (bending), the PCW (sticky tape) shows few dislocations as we see in non-image ancient fibers (Fig. 18, upper image, right side).

-3. If the flax fiber (rubber band) has been previously stressed, covered with the PCW (sticky tape) and finally released, a greater number dislocations are evident as we see in image-fibers (Fig. 18, lower image).

Case (3) is a model of what seems to happen in image-fibers: their SCW is not obviously pre-tensioned before it has been covered by the PCW, but the final behavior is elastically equivalent. In fact the flax fibers exposed to intense radiations, have their cellulosic SCW retracted, thus producing the evident corrugations of PCW.

\section{Color analysis}

The background color of the TS is not uniform; Fig. 19 shows two reflectance spectra in the visible range made on brighter and darker parts using Color-Eye 7000A of Ritex (Vicenza, Italy) by Roberta Binotto. These spectra are compatible with those determined during STURP campaign in 1978 and confirm the absence of additional pigments.

The mean CIELAB values obtained from four different measurements are the following:

- Bright parts: $\mathrm{L}=71.58, \mathrm{a}=4.20, \mathrm{~b}=18.81(\mathrm{R}=196, \mathrm{G}=172, \mathrm{~B}=141)$.

- Dark parts: $\mathrm{L}=64.66, \mathrm{a}=5.26, \mathrm{~b}=21.97(\mathrm{R}=180, \mathrm{G}=152, \mathrm{~B}=118)$.

As the dark parts correspond to polluted areas, the bright parts have been considered for a comparison with the environmental conditions in which the TS was exposed during 1532 Chambéry fire. 


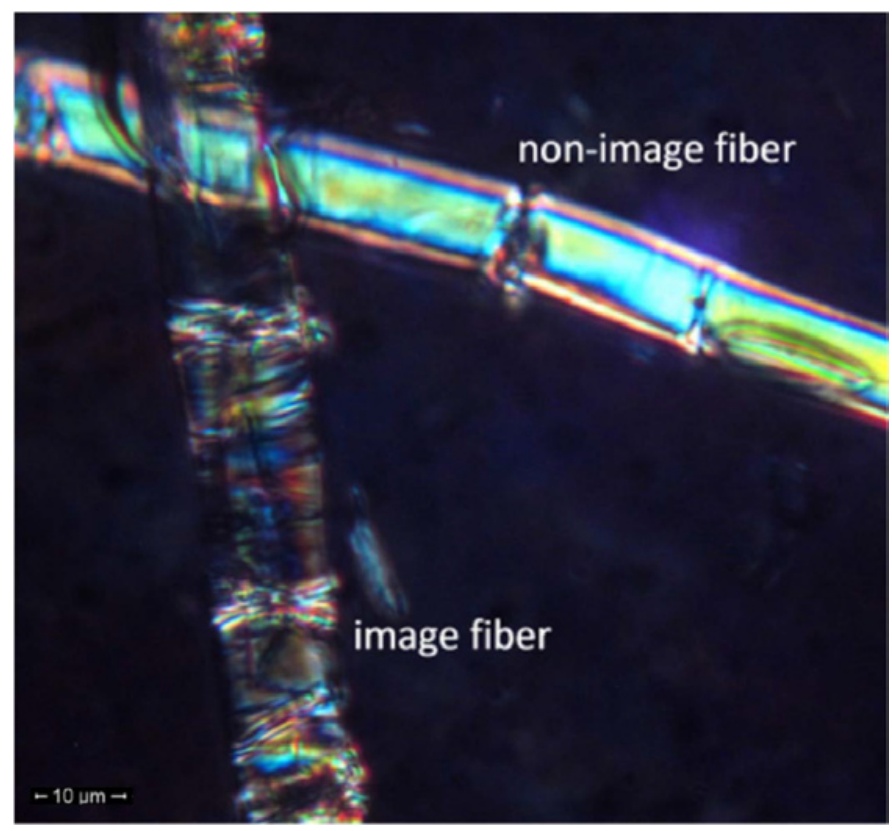

Figure 16. Modern flax fibers seen in cross-polarized light after exposition to Corona Discharge: image-fiber and non-image-fiber. The corrugation of PCW on image-fiber is well evident.

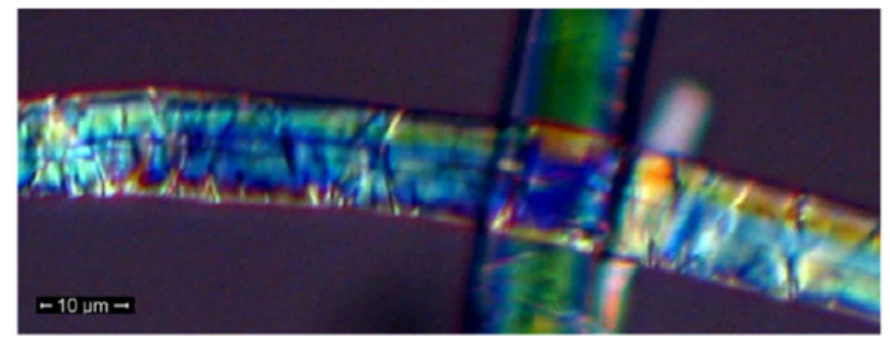

Figure 17. Modern flax fibers seen in cross-polarized light after exposition to Excimer laser: image-fiber (horizontal) and non-image-fiber (vertical). The corrugation of PCW on image-fiber is well evident.

Many samples of TS-like fabric (made by Liotex, Italy) have been exposed by Dr. Stefano Dall'Acqua (Padua University) to various heating sources for different time periods using an oven. The corresponding colors have been compared (Fig. 20) to that of the TS in order to define the worst condition to which it could have been exposed during the 1532 fire.

A direct comparison of color shows that the TS was not exposed to heat sources harder than about $300^{\circ} \mathrm{C}$ for 5 minutes, $220^{\circ} \mathrm{C}$ for 30 minutes, $200^{\circ} \mathrm{C}$ for 60 minutes or $180^{\circ} \mathrm{C}$ for 240 minutes.

Considering the additional yellowing effect of the TS due to age, the above mentioned limits should be reduced to the following: about $250^{\circ} \mathrm{C}$ for 5 minutes, $200^{\circ} \mathrm{C}$ for 30 minutes, $180^{\circ} \mathrm{C}$ for 60 minutes or $160^{\circ} \mathrm{C}$ for 240 minutes.

Considering the almost uniform color of the TS that was folded during the 1532 fire, and the fact that the flax fabric is a bad heat conductor, it must be supposed that it was exposed to a relative long time. It therefore results that the TS was probably exposed to a heat source not harder than about $180^{\circ} \mathrm{C}$ for 60 minutes or $160^{\circ} \mathrm{C}$ for 240 minutes. 


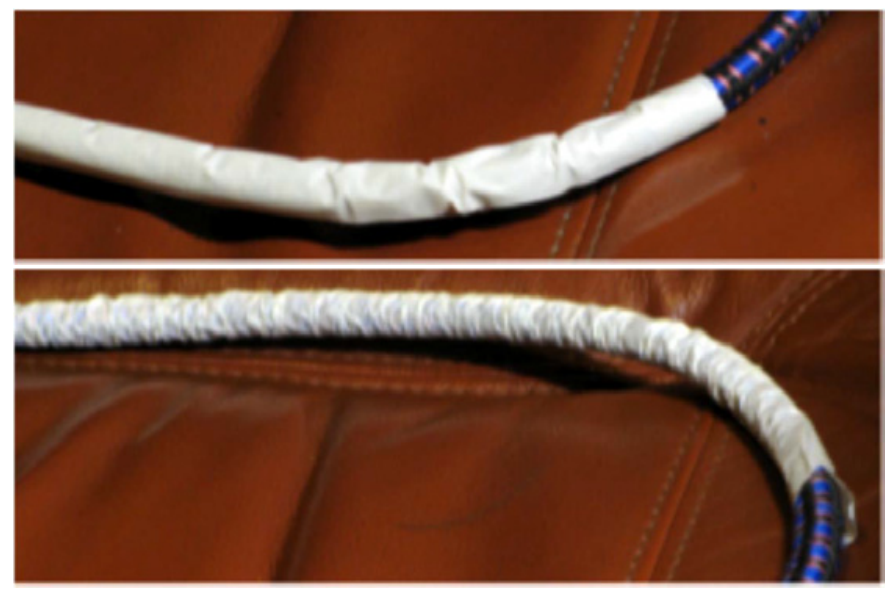

Figure 18. Experiment. Rubber band (blue) covered by a stiffer sticky tape (white). The rubber band, on the upper image, shows few "dislocations" in correspondence of its bending; this can be compared with the dislocations detected in non-image fibers. The pre-tensioned rubber band on the lower image has been covered by a sticky tape and then released. The surface of this composite system appears much more corrugated as it can be detected in the PCW of image-fibers.

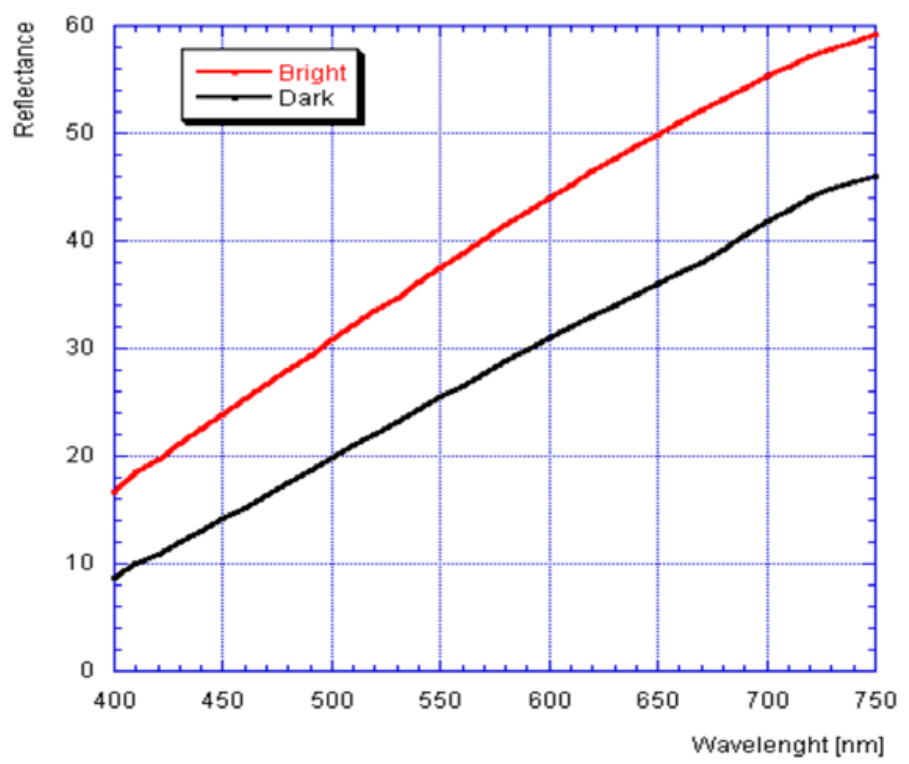

Figure 19. Visible spectra of some bright and dark parts of the TS background.

It must therefore be supposed that the much harder heat conditions developed during the 1532 fire were probably damped by an hypothetical protective cloth in which the TS was wrapped before being put in the reliquary.

As a partial confirmation of the fact that the TS was contained in a silver reliquary when subjected to the Chambéry fire, the ESEM (Environmental Scanning Electron Microscope) analysis reported in Fig. 21 shows the presence of a silver particle deposited on a flax fiber also in correspondence of the EDAX (Energy Dispersive X-ray Analysis) spectrum. Incidentally it must be observed that the shape of 
ATSI 2014

\begin{tabular}{|c|c|c|c|}
\hline $\begin{array}{c}150^{\circ} \\
5^{\prime}\end{array}$ & $\begin{array}{c}150^{\circ} \\
30^{\circ}\end{array}$ & $\begin{array}{c}150^{\circ} \\
60^{\circ}\end{array}$ & $\begin{array}{l}150^{\circ} \\
120^{\prime}\end{array}$ \\
\hline $\begin{array}{c}200^{\circ} \\
5^{\prime}\end{array}$ & $\begin{array}{c}200^{\circ} \\
30^{\circ}\end{array}$ & $\begin{array}{c}200^{\circ} \\
60^{\circ}\end{array}$ & $\begin{array}{l}200^{\circ} \\
120^{\circ}\end{array}$ \\
\hline $\begin{array}{c}250^{\circ} \\
5^{\prime}\end{array}$ & $\begin{array}{c}250^{\circ} \\
30^{\prime}\end{array}$ & $\begin{array}{c}250^{\circ} \\
60^{\circ}\end{array}$ & $\begin{array}{l}250^{\circ} \\
120^{\circ}\end{array}$ \\
\hline $\begin{array}{l}150^{\circ} \\
180^{\circ}\end{array}$ & $\begin{array}{l}180^{\circ} \\
180^{\circ}\end{array}$ & $\begin{array}{l}200^{\circ} \\
180^{\circ}\end{array}$ & $\begin{array}{l}220^{\circ} \\
180^{\circ}\end{array}$ \\
\hline $\begin{array}{l}150^{\circ} \\
240^{\circ}\end{array}$ & $\begin{array}{l}180^{\circ} \\
240^{\prime}\end{array}$ & $\begin{array}{l}200^{\circ} \\
240^{\prime}\end{array}$ & $\begin{array}{l}220^{\circ} \\
240^{\circ}\end{array}$ \\
\hline $\begin{array}{l}150^{\circ} \\
300^{\prime}\end{array}$ & $\begin{array}{l}180^{\circ} \\
300^{\circ}\end{array}$ & $\begin{array}{l}200^{\circ} \\
300^{\prime}\end{array}$ & $\begin{array}{l}220^{\circ} \\
300^{\prime}\end{array}$ \\
\hline
\end{tabular}

Figure 20. Resulting colors of TS-like samples exposed in an oven with corresponding temperatures $\left[{ }^{\circ} \mathrm{C}\right]$ and time periods [minutes] put on a background color corresponding to that of the TS.
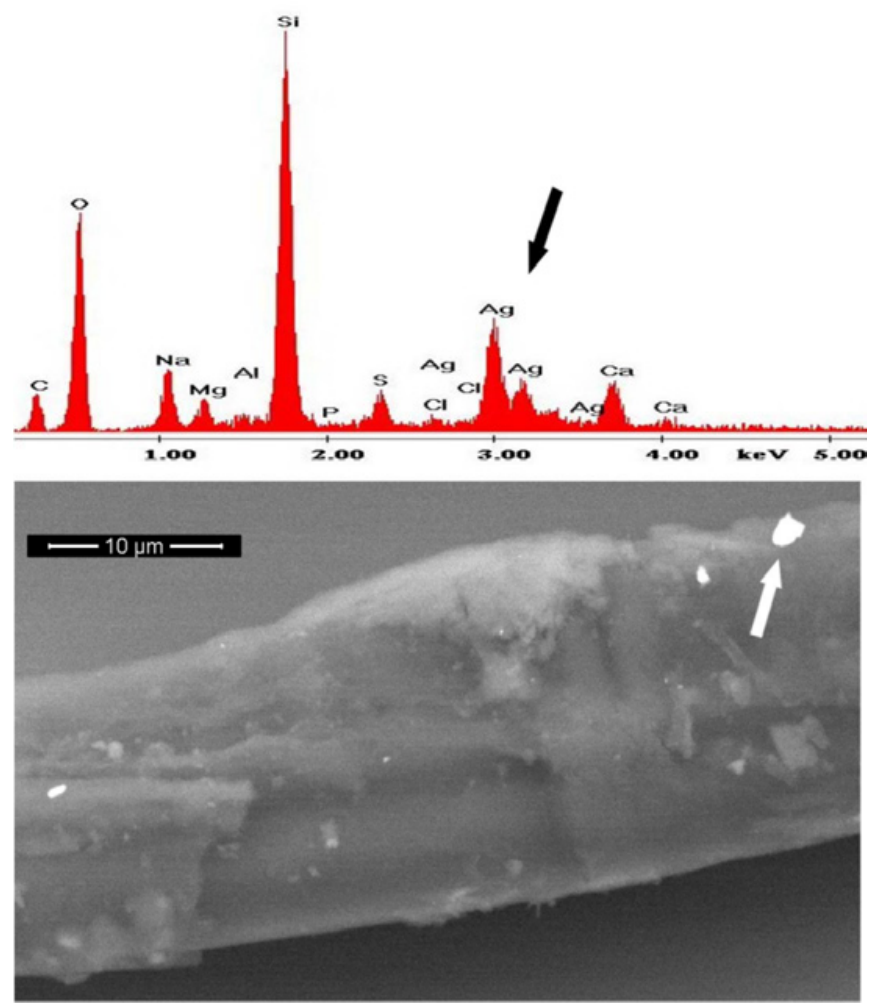

Figure 21. ESEM photo of a TS flax fiber containing a silver particle (white arrow) with relative EDAX spectrum showing the presence of $\mathrm{Ag}$ (black arrow). 

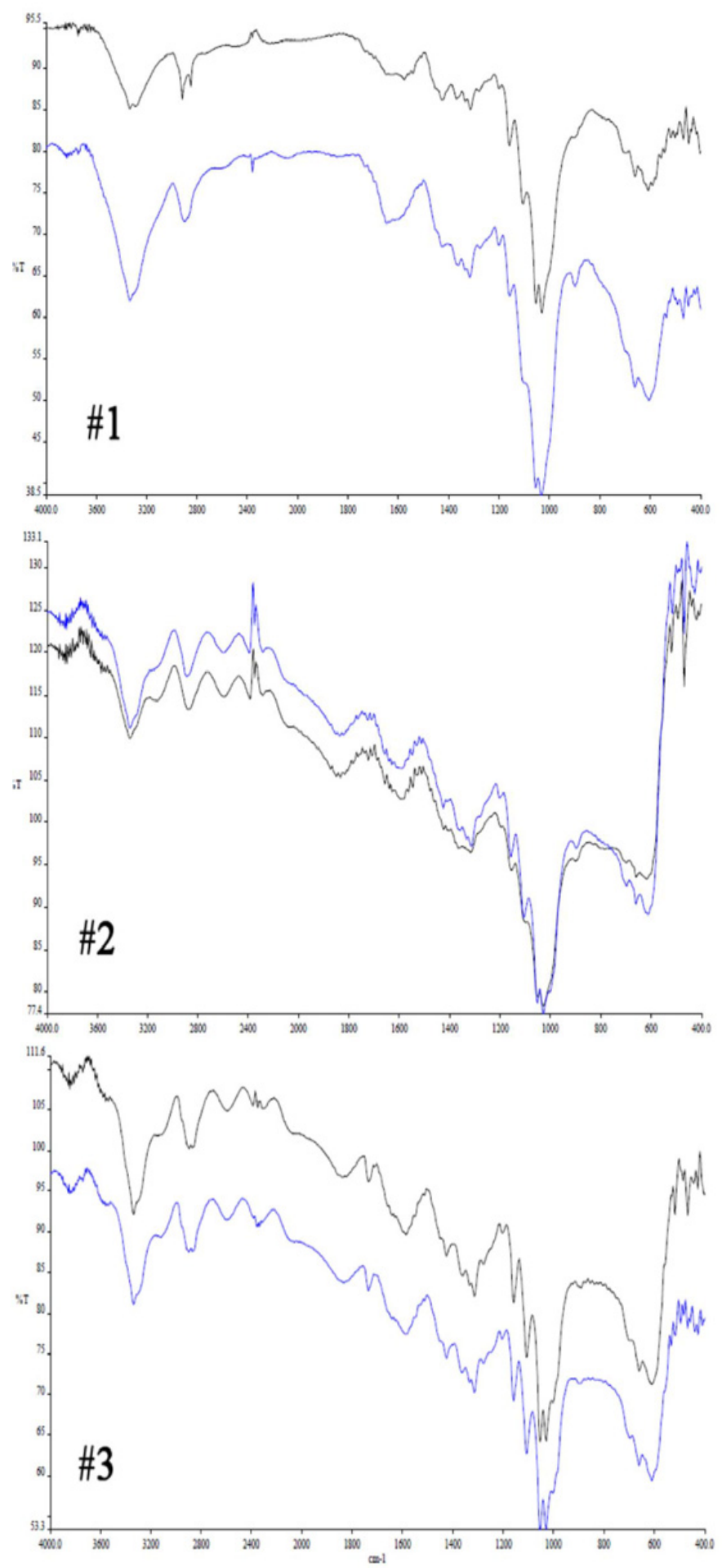

Figure 22. Transmittance FT-IR spectra of TS fibers: \#1 corresponds to a corner area, \#2 to the gluteal area and \#3 the Hands area. The wavenumbers in abscissas are expressed in $\mathrm{cm}^{-1}$. 


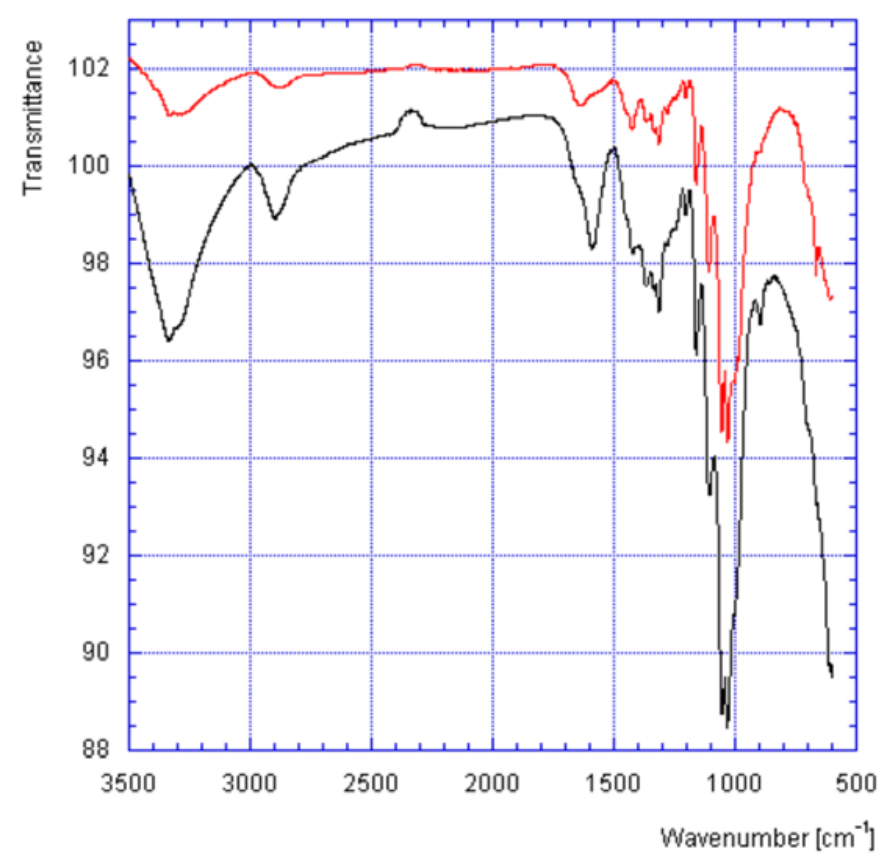

Figure 23. Transmittance FT-IR spectra of a TS image-fiber (black, lower plot) coming from the sticky tape STURP-1EB and a non-image-fiber (red, upper plot) coming from a corner of the TS.

the TS holes seem not coherent with drops of melted silver or lead coming from the reliquary, but are congruent with the effects of a fiery beam perhaps falling from the church's roof that broke the reliquary and pierced all the layers of the folded Relic.

\section{Opto-chemical analysis}

FT-IR ATR analysis performed on various flax fibers coming from the TS, see Fig. 22, shows some spectra resulting from a Perkin Elmer Spectrum 2000 of Dedalo Srl (Vicenza, Italy).

Spectrum \#1 corresponds to flax fibers coming from a TS corner, while spectrum \#2 and \#3 respectively refer to flax fibers coming from the gluteal area and the Hands area of the TS.

It can be observed that, while spectra \#2 and \#3 are quite similar, some differences arise in spectra \#1 both for the absence of the peak at about $1800 \mathrm{~cm}^{-1}$ and the behavior at about $1600 \mathrm{~cm}^{-1}$. The band between $1620 \mathrm{~cm}^{-1}$ and $1640 \mathrm{~cm}^{-1}$ corresponds to the $\mathrm{O}-\mathrm{H}$ bending, the peak at $1739 \mathrm{~cm}^{-1}$ corresponds to the $\mathrm{C}=\mathrm{O}$ stretching typical of ester vibrations of lignin, while the peak of spectra \#3 at $1720-1730 \mathrm{~cm}^{-1}$ corresponds to the $\mathrm{C}=\mathrm{O}$ stretching due to photo oxidation of the sample [23].

According to Prof. Anna Tinti of Bologna University, the two spectra \#1 show a significant difference in the band at about $2850 \mathrm{~cm}^{-1}$ : while the upper spectrum is split into two components, the lower one is given by one single band. In addition there are other differences in the intensity bands there around, which would suggest the possible contamination of wax on the fabric. Contamination of foreign material make therefore not easy the comparison among the spectra of Fig. 22.

FT-IR ATR analysis has also been performed on one TS image-fiber comparing it with a non-image TS fiber. Figure 23 shows the relative spectra kindly furnished by Maria Grazia Garavaglia of Perking Elmer using Spectrum 100 analyzer. 


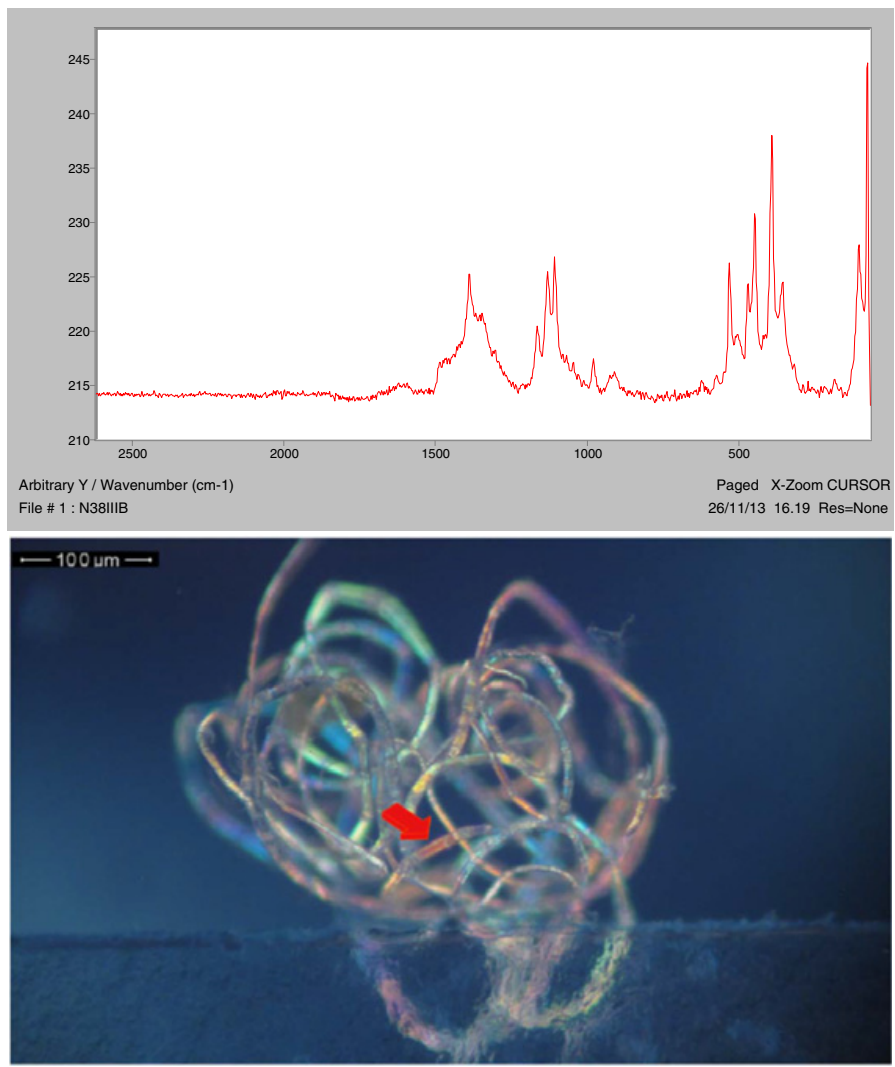

Figure 24. Baseline corrected Raman spectrum of a TS flax fiber (coming from the gluteal area of the Man) photographed below in cross-polarized light. The arrow shows the part of the fiber tested.

As confirms A. Tinti, Italy, the image-fiber spectrum shows a more oxidized, dehydrated and conjugated area of the flax fiber and therefore typical of a body image area.

Both the relative bands at $1053 \mathrm{~cm}^{-1}$ and at $3340 \mathrm{~cm}^{-1}$ increase in STURP-1EB sample of image-fiber thus indicating a more intense presence of secondary alcohol derived from a hydrocarbon, by substitution of one or more hydrogen atoms with many hydroxyl groups-OH. The dehydration in this sample is confirmed by the variation of the intensity of the $1640 \mathrm{~cm}^{-1}$ band.

A Raman analysis in the IR has been recently performed at Milano University by Paolo Tiberio [24] who tested more than 30 flax fibers coming from the author's collection. Previous Raman analyses on similar fibers have been done at Modena University by Pietro Baraldi who used a visible laser beam but the results were not easy to study because of the presence of a high level of fluorescence.

The IR Raman analysis of P. Tiberio has been performed at Jasco Analytical Instruments (Cremella, Italy) using a JascoNRS-5100 instrument. Figure 24 shows the results relative to a flax fiber coming from the gluteal area of the TS Man. If compared with the spectra of a previous work [25], there is a difference at lower wavelengths: this spectrum evidences intense peaks in the range from about $400 \mathrm{~cm}^{-1}$ to $500 \mathrm{~cm}^{-1}$ that are typical of CCC and COC groups $[26,27]$.

\section{Conclusive remarks}

The study of some optical features of the flax fibers coming from the TS, using both optical and petrographic microscopes, SEM and opto-chemical spectrometry has confirmed their peculiarities. 
Raman and FT-IR analyses confirm some chemical information relative to the TS image-fibers: the image is not made by pigments but is caused by an oxidation, dehydration and conjugation of the polysaccharides PCW about $200 \mathrm{~nm}$ thick.

The results of a color analysis of flax samples exposed to different heat sources, compared with the TS background color, lead to hypothesize that it was wrapped in a protective cloth when put in the reliquary during the 1532 Chambéry fire and it was probably exposed to a heat source not harder than about $180^{\circ} \mathrm{C}$ for 60 minutes or $160^{\circ} \mathrm{C}$ for 240 minutes.

Cross-polarization is a very useful tool in the identification of TS flax fibers mixed with modern ones in the dusts vacuumed during the 1978 campaign because of their "coral-snake" appearance. Their greater number of dislocations, typical of ancient fibers subjected to a beating procedure during the extraction procedure from the plants, makes them easy to recognize from modern flax fibers that are extracted in a different way.

The colored TS fibers show color only in correspondence of their PCW, while their cellulosic SCW appears not colored. Both optical microscope and SEM show that the external surface of the TS fibers is quite encrusted due to the presence of mildew and calcareous deposits.

PLM has also evidenced a peculiar feature of some flax fibers coming from the TS gluteal area: there are almost periodical areas along the fiber length that appear as "burnt" and/or "dried": they seem only composed of the PCW, without the SCW. This feature can be related with a masking effect from an intense radiation produced by the threads crossing these fibers in the weave.

Image-fibers of the TS present a very corrugated PCW that can be related to a SCW shrinking, probably due to an intense source of radiation. Both Corona Discharge and Excimer Lasers experiments performed to color modern flax fibers are able to reproduce this behavior, thus confirming the hypothesis of a TS body image formation related to an intense burst of energy.

This study is one of the results obtained from the financial support of the University Research Project-Padova, Italy-2009 \#CPDA099244 entitled: "Multidisciplinary analysis applied to the Shroud of Turin: A study of body image, of possible environmental pollution and of microparticles characterizing the linen fabric."

Particular thanks to Raymond Rogers and other STURP scientists who kindly furnished samples of the TS taken during 1978 campaign.

The author also thanks prof. Anna Tinti of Bologna University, Italy for the advices relative to FT-IR spectrometry, dr. Maria Grazia Garavaglia of Perkin Elmer for the spectra of the TS image-fiber, Dr. Roberta Binotto of Ritex for the visible spectra of the TS, Dr. Stefano Dall'Acqua of Padua University for the oven test of TS-like samples and the team of Milan University leaded by prof. Silvia Bruni that allowed dr. Paolo Tiberio to obtain a degree thesis on Raman analysis of ancient flax fibers.

A particular thanks to prof. Giuseppe Zagotto of Padua University who controlled the chemical aspects and allowed the author to have many FT-IR spectra of flax fibers from Dedalo srl, Italy.

\section{References}

[1] Jumper, E.J., Adler A.D., Jackson J.P., Pellicori S.F., Heller J.H., Druzik J.R., “A comprehensive examination of the various stains and images on the Shroud of Turin", Archaeological Chemistry III, ACS Advances in Chemistry n ${ }^{\circ}$ 205, J.B. Lambert, Editor, Chapter 22, American Chemical Society, Washington D.C., 1984, pp. 447-476

[2] Adler A. , A Shroud Spectrum Int. Special Issue, Effatà Editrice, Torino, Italy (2002)

[3] Vignon P., "The Shroud of Christ", E.P. Dutton \& Co. New York 1902

[4] Schwalbe, L.A., Rogers R.N., "Physics and chemistry of the Shroud of Turin, a summary of the 1978 investigation", Analytica Chimica Acta, Vol. 135, 1982, pp. 3-49

[5] Enrie G., "La Santa Sindone rivelata dalla fotografia", Società Editrice Internazionale, Torino, 1933

[6] J.P. Jackson, E.J. Jumper, and W.R. Ercoline, "Correlation of image intensity on the Turin Shroud with the 3-D structure of a human body shape", Appl. Opt. 23, 2244-2270 (1984) 
[7] G. Fanti and R. Maggiolo, "The double superficiality of the frontal image of the Turin Shroud", J. Opt. A, Pure Appl. Opt. 6, 491-503 (2004)

[8] P. Di Lazzaro, D. Murra, B. Schwortz, "Pattern recognition after image processing of low-contrast images, the case of the Shroud of Turin", Pattern Recognition J., 46 (2013), 1964-1970

[9] G. Fanti, R. Maggiolo, "About the second image of face detected on the Turin Shroud", Int. Conference on the "Shroud of Turin: the Controversial Intersection of Faith and Science", St. Louis, Missouri, October 2014, www . shroud.com/pdfs/stlfanti1.pdf

[10] G. Fanti, J.A. Botella, F. Crosilla, F. Lattarulo, N. Svensson, R. Schneider, A.D. Whanger "List of Evidences of the Turin Shroud", Int. Workshop on the Scientific Approach to the Acheiropoietos Images, ENEA Research Center of Frascati (Italy), 4-5-6 May 2010

[11] G. Fanti, J.A. Botella, P. Di Lazzaro, T. Heimburger, R. Schneider, N. Svensson," Microscopic and Macroscopic Characteristics of the Shroud of Turin Image Superficiality", J. of Imaging Sci. Technol., 54, No. 4, p. 040201-1/8 (2010)

[12] G. Fanti, "Hypotheses regarding the formation of the body image on the Turin Shroud. A critical compendium", J. of Imaging Sci. Technol., Vol. 55, No. 6, p. 060507 (Dec. 22 2011)

[13] G. Fanti, R. Basso, "Statistical Analysis Of Dusts Taken From Different Areas Of The Turin Shroud", Proc. of Int. Conf., Ohio State University, August 14-17, 2008, Libreria Progetto, Padova, Italy 2009

[14] G. Saldarini, "Dichiarazione sugli esperimenti riguardanti la Santa Sindone" Open Letter, Section d. September 1995, Turin, Italy

[15] G. Fanti, P. Malfi, "A New Cyclic-Loads Machine For The Measurement Of Micro-Mechanical Properties Of Single Flax Fibers Coming From The Turin Shroud", AIMETA Congress, Torino, 2013

[16] G. Fanti, P. Malfi, “Sindone, primo secolo dopo Cristo!” , Ed. Segno, Tavagnacco, Udine, Italy, 2014, ISBN 978-88-61-38785-0

[17] W.C. McCrone, L.B. McCrone, J.G. Delly, "Polarized Light Microscopy", Ann Arbor Science Pub. Michigan, USA (1978)

[18] H.L. Bos, A.M. Donald, "In situ ESEM study of the deformation of elementary flax fibres", J. of Materials Science 34 (1999), p. 3029-3034

[19] G. Fanti, "Can a Corona Discharge Explain the Body Image of the Turin Shroud?", Journal of Imaging Science and Technology, Vol. 54, No. 2, March/April 2010, p. 020508-1/10

[20] L.G. Thygesen, "Dislocations in plant fibres and in Turin Shroud fibres", Proc. Int. Workshop on the Scientific approach to the Acheiropoietos Images, ENEA Frascati, Italy, 4-6 May 2010

[21] Pliny the Elder, "Naturalis Historia", Book XIX, Section III, 16, 77 A.D.

[22] G. Baldacchini, P. Di Lazzaro, D. Murra, G. Fanti: "Coloring Linens by Excimer Lasers to Explain the Body Image of the Turin Shroud" Applied Optics Vol. 47, No. 9, 20 (2008)

[23] L.M. Proniewicz, C. Paluszkiewicz, A. Weselucha-Birczynska, H. Majcherczyk, A. Baranski, A. Konieczna, J. Mol. Struct. 596 (2001), 163-9

[24] P. Tiberio, "Studio mediante spettroscopia Raman di fibre di lino da tessuti antichi" (Study by means of Raman spectroscopy of flax fibders from ancient textiles), degree thesis, supervisors Prof. Silvia Bruni, Giulio Fanti (external), Letizia Bomnizzoni and Nicola Ludwig, Milan University, Italy, a. year 2012-2013

[25] G. Fanti, P. Baraldi, R. Basso, A. Tinti, Non-destructive dating of ancient flax textiles by means of vibrational spectroscopy, Vibrational Spectroscopy (2013), 10.1016/j.vibspec.2013.04.001

[26] M. Szymanska-Chargot, J. Cybulska, A. Zdunek, "Sensing the Structural Differences in Cellulose from Apple and Bacterial Cell Wall Materials by Raman and FT-IR Spectroscopy", Sensors, (2011), 11, 5543-5560

[27] H.G.M. Edwards, N.F. Nikhassan, D.W. Farwell, P. Garside, P. Wyet, "Raman spectroscopic analysis of a unique linen artifact: the HMS Victory Trafalgar sail", J. of Raman Spectroscopy, (2006), Vol. 37, 1193-1200 